\title{
Análisis del discurso jurídico y político en la época contemporánea
}

\author{
María Alejandra Tapia-Millán* \\ Diana Cristina Ruiz-Ariza ${ }^{\star *}$ \\ Yordy Esteban Rojas-Porras ${ }^{* * *}$ \\ Luis Alfredo Ordóñez-Pardo ${ }^{\star * * *}$
}

\footnotetext{
Candidata a doctora en Psicología, Universidad de los Andes. Magíster en Psicopatologías Clínicas del Sujeto y del Lazo Social, Universidad de Toulouse-Jean Jeaurès. Profesora-investigadora, Facultad de Derecho, Universidad Cooperativa de Colombia, Bogotá, Colombia.

Correo electrónico:

alejatapia36@gmail.com.

** Estudiante, Facultad de Derecho, Universidad Cooperativa de Colombia, Bogotá, Colombia.

Correo electrónico:

diana.ruiz@telealdia.co.

*** Estudiante, Facultad de Derecho, Universidad Cooperativa de Colombia, Bogotá, Colombia.

Correo electrónico:

esteban1057@hotmail.es.

****Estudiante, Facultad de Derecho, Universidad Cooperativa de Colombia, Bogotá, Colombia.

Correo electrónico:

alfredo.ordonez.pardo@gmail.com.
}

Recibido: 16 de julio del 2015

Aprobado: 12 de diciembre del 2015

Cómo citar este artículo: María Alejandra

Tapia-Millán, Diana Cristina Ruiz-Ariza,

Yordy Esteban Rojas-Porras, Luis Alfredo

Ordóñez-Pardo. Análisis del discurso jurídico

y político en la época contemporánea. DIXI

23. Abril 2016. Pág. 71. doi: http://dx.doi.

org/10.16925/di.v18i23.1292

\section{Resumen}

Propósito: a partir de la inquietud del filósofo italiano Giorgio Agamben acerca del significado ético, jurídico y político del exterminio, se avanza hacia el análisis del nuevo paradigma del espacio político moderno, en su esencia, determinado por un tipo de exclusión que se mantiene vigente hasta nuestros días. Descripción: en este recorrido, se retomará el concepto de biopolítica, con el propósito de comprender el dispositivo que permite la emergencia de la nuda vida en el seno del espacio político, a saber, el estado de excepción. Punto de vista: en este punto del artículo, la reflexión se centra en el problema del testimonio de los sobrevivientes de los campos de concentración, lugar en el que se halla, paradójicamente, una vía alterna a este reino entre la vida y la muerte que ha impuesto el discurso político contemporáneo. Conclusiones: esto último abre como horizonte la cuestión de lo femenino como otra posible forma de establecer un lazo social, para lo cual se retomarán conceptos psicoanalíticos con miras a comprender la lógica femenina y sus incidencias en la configuración subjetiva y social.

Palabras clave: biopolítica, estado de excepción, femenino, testimonio. 


\title{
Analysis of Legal and Political Discourse in Contemporary Times
}

\begin{abstract}
Purpose: from the concern of the Italian philosopher Giorgio Agamben on the ethical, legal and political meaning of extermination, we advance towards the analysis of a new paradigm of modern political space in essence, determined by a type of exclusion that remains in force to the present day. Description: this overview will take up the concept of biopolitics in order to understand the device that allows the emergence of bare life within the political space, namely, the state of exception. Point of view: at this point of the article, reflection centers on the problem of the testimony of survivors from concentration camps, a place where there is paradoxically an alternate pathway to this kingdom between life and death imposed by the contemporary political discourse. Conclusions: the latter opens a horizon for the woman question as another form of establishing social bonds, for which psychoanalytical concepts will be taken up in order to understand the feminine logic and their incidence in subjective and social shaping.
\end{abstract}

Keywords: biopolitics, state of exception, feminine, testimony.

\section{Análise do discurso jurídico e político na época contemporânea}

\section{Resumo}

Propósito: a partir da inquietude do filósofo italiano Giorgio Agamben acerca do significado ético, jurídico e político do extermínio, avança-se em direção à análise do novo paradigma do espaço político moderno, em sua essência, determinado por um tipo de exclusão que se mantém vigente até nossos dias. Descrição: neste estudo, será retomado o conceito de biopolítica com o propósito de compreender o dispositivo que permite a emergência da nua vida no seio do espaço político, a saber, o estado de exceção. Ponto de vista: neste ponto do artigo, a reflexão centrase no problema do testemunho dos sobreviventes dos campos de concentração, lugar no qual se acha, paradoxalmente, um caminho alterno a este reino entre a vida e a morte que impôs o discurso político contemporâneo. Conclusões: este último abre como horizonte a questão do feminino como outra possível forma de estabelecer laço social; para isso, serão retomados conceitos psicanalíticos com o objetivo de compreender a lógica feminina e suas incidências na configuração subjetiva e social.

Palavras-chave: biopolítica, estado de exceção, feminino, testemunho. 


\section{INTRODUCCIÓN ${ }^{1}$}

El artículo que a continuación se presenta es el resultado del trabajo adelantado por el semillero de investigación Cultura, Derecho y Psicoanálisis, de la Facultad de Derecho de la Universidad Cooperativa de Colombia, sede Bogotá, en el marco de un proyecto de investigación sobre lecturas alternativas a los desafíos éticos, jurídicos y políticos que se suscitan en el contexto actual de las negociaciones entre la guerrilla de las FARC y el Gobierno. El mencionado proyecto se inscribe en un plan de trabajo financiado por Colciencias (Convocatoria 617 de 2014), en el cual se propuso repensar el lugar de la democracia moderna y los lazos de segregación y exclusión que allí surgen, así como reflexionar acerca de las relaciones que se dan entre el poder soberano y los estados de excepción, y sus efectos sobre el ordenamiento jurídico y los sujetos. ${ }^{2}$ Es por lo anterior que el semillero, más allá de erigirse como un lugar de reflexión académica, se constituye a partir de un llamado ético que moviliza a aportar elementos de análisis y de reflexión que permitan dar respuestas más precisas a estos interrogantes, los cuales en definitiva no son solo teóricos, sino que remiten a la manera como se configura el futuro de la sociedad colombiana.

En relación con los dos campos de reflexión que convergen en el artículo, a saber, el psicoanálisis y el Derecho, resulta preciso distinguir la noción de sujeto que el primero introduce. Se trata de un sujeto

1. El presente artículo retoma algunos elementos de una ponencia presentada en la v Jornada Estudiantil de Filosofía del Derecho, Ética y Política, evento que tuvo lugar en la Universidad Libre de Colombia en los días 24 y 25 de octubre de 2013, bajo el título "Lo femenino como respuesta al discurso socio-político moderno". 2. Sobre esto, y en relación con el contexto colombiano, vale recordar que en Colombia el estado de excepción se convirtió, por lo menos hasta 1991, en un instrumento ordinario de la política gubernamental. He aquí cuatro indicaciones de esta anomalía: 1. La excepción era casi permanente. Así, por ejemplo, en los 21 años transcurridos entre 1970 y 1991, Colombia vivió 206 meses bajo estado de excepción, es decir, 17 años, lo cual representa el $82 \%$ del tiempo transcurrido. Entre 1949 y 1991 Colombia vivió más de 30 años bajo estado de sitio; 2. Buena parte de las normas de excepción han sido legalizadas por el Congreso, lo cual ha convertido al Ejecutivo en un legislador de hecho; 3. Hubo periodos en los cuales se impusieron profundas restricciones a las libertades, el $30 \%$ de los delitos del Código Penal eran competencia de cortes marciales. En Colombia la excepción ha propiciado el desvanecimiento de la frontera entre lo legal y lo ilegal, y por esta vía ha facilitado el salto hacia el no-derecho, no solo de funcionarios del Estado, sino también de particulares. Véase Mauricio García Villegas. Un país de estados de excepción. Elespectador.com. Octubre 11 de 2008. Disponible en http:// www.elespectador.com/impreso/politica/articuloimpreso43317un-pais-de-estados-de-excepcion articulado a la ley y al lazo social, y que surge precisamente como efecto de estos. Ahora bien, se entrevé el porqué de la posibilidad y, aún más, de la necesidad de que el Derecho entre en diálogo con el psicoanálisis, en la medida en que son la ley y el sujeto de lo que ambos se ocupan. En este sentido, el entrecruzamiento del discurso jurídico y el discurso psicoanalítico ofrece la posibilidad de acercarse a temas tan complejos pero decisivos para el conjunto de la sociedad, tales como el crimen, la sanción penal, la culpa, la reincidencia de los delincuentes y la violencia, entre otros, a la vez que permite indagar sobre el lugar que le cabe al sujeto dentro de estos fenómenos sociales.

Teniendo en cuenta lo anterior, podría afirmarse que el psicoanálisis y el Derecho, lejos de existir como un par de opuestos, se ubican en una serie de continuidades dentro de las cuales sería imposible concebir al uno sin el otro. Son estas dos disciplinas las que se ocupan de la subjetividad humana, su objeto por excelencia son "los sujetos humanos tomados en tanto que cuerpos vivientes, efectos de la Ley y de las leyes que ellos habitan". ${ }^{3}$ Así, se puede afirmar que el entrecruce entre el Derecho y el Psicoanálisis permite analizar y explicar las causas más profundas del comportamiento humano, así como las coordenadas sociales que lo atraviesan. Por esto, se hace urgente desarrollar investigaciones que le den lugar a estos dos discursos: el jurídico y el psicoanalítico, ya que de permanecer divorciados, la pérdida queda del lado del abordaje que se le puede dar a la subjetividad humana.

En Colombia, la profunda problemática social hace evidente la falta de eficacia de las normas jurídicas no solamente en fenómenos como la corrupción, el conflicto armado o las altas tasas de impunidad, también en el transcurrir cotidiano de los grupos sociales se hace referencia a la relación subjetiva de cada uno con la ley. ${ }^{4}$ La necesidad de ahondar en el

3. Véase Néstor Braunstein. Los dos campos de la subjetividad: Derecho y Psicoanálisis. Gerez Ambertín, Ed. CulPA, RESPONSABILIDAD Y CASTIGO EN EL DISCURSO JURÍDICO Y PSICOANALÍTICO VoL. 1. Letra Viva. (2006). Pág. 20

4. En este orden de ideas, a partir de la noción de relación subjetiva con la ley se puede afirmar que, para que el enunciado de la ley cumpla algún papel en la vida del sujeto, es preciso que el sujeto realice un asentimiento subjetivo de la ley, esto es, que la ley sea el resultado de una elección. De lo contrario, la ley pierde su potencia simbólica para quedar apenas reducida a un puro mandato, puro bando: "la forma vacía de una vigencia sin significado". Véase Giorgio Agamben. Homo SACER. El PODER SOBERANO Y LA NUDA vidA. Pre-textos. (1998). Pág. 80. Así mismo, el reconocimiento de este requerimiento de un posicionamiento del sujeto frente a la ley "es una condición para permitir que la ley cumpla su función civilizadora”. Véase Pierre Bruno. ¿QUÉ ES UNA LEY? Escuela de Estudios 
diagnóstico y el conocimiento de esta brecha entre ley y lazo social invita a formular investigaciones que permitan acercar el Derecho a las realidades sociales, políticas, económicas y subjetivas del país, cuestión que pretende generar propuestas originales y novedosas que tengan resonancia en el conjunto de la sociedad.

De tal manera, este artículo busca, a partir de algunos de los desarrollos teóricos propuestos por el filósofo italiano Giorgio Agamben, analizar el dispositivo que permite la emergencia de la nuda vida en el seno del espacio político contemporáneo, a saber, el estado de excepción. En particular, se retomarán las inquietudes formuladas por Agamben acerca del significado ético, jurídico y político del exterminio, las cuales le permiten postular la tesis de la configuración de un nuevo paradigma del espacio político moderno, en su esencia determinado por un tipo de exclusión que se mantiene vigente hasta nuestros días. En el marco de estas discusiones, aparece el problema del testimonio de los sobrevivientes de los campos de concentración, lugar donde el autor encuentra una respuesta ética al reino entre la vida y la muerte que ha impuesto el discurso político contemporáneo. El artículo finaliza con una discusión que articula el asunto del testimonio con los desarrollos psicoanalíticos acerca de la lógica femenina y sus incidencias en la configuración subjetiva y social, y con una reflexión sobre el lugar del arte en la política.

La propuesta de investigación fue de orden cualitativo y teórico, y se desarrolló a partir de la revisión y discusión de textos teóricos.

\section{Agamben, Biopoder Y ESTADOS DE EXCEPCIÓN}

¿A qué se hace referencia cuando se habla de discurso sociopolítico moderno? La humanidad está sumergida en una situación en la que el Estado ejerce un control sobre la vida de los ciudadanos. Retomando el concepto de Michel Foucault, ${ }^{5}$ se trata del imperio de la biopolítica. Esta alude al manejo político de la vida, esto es, la administración de la vida por parte del Estado, tomada como mera vida biológica.

El propósito del presente escrito es plantear diferentes posibilidades de abordar el actual sistema

en Psicoanálisis y Cultura, Universidad Nacional de Colombia [inédito]. Pág. 5.

5. Véase Michel Foucault. Historia de la Sexualidad i. LA voluntad de SABER. Fondo de Cultura Económica. (2007). político predominante en la sociedad contemporánea, caracterizado por "la administración de los cuerpos y la gestión calculadora de la vida". ${ }^{6}$ Se busca así construir elementos de análisis que permitan brindar respuestas más precisas, las cuales remitan a la reflexión de otras posibles formas de establecer un lazo social.

Bajo las anteriores premisas, es importante abordar el pensamiento de Giorgio Agamben y su emblemático trabajo del estudio del biopoder en los textos denominados "Homo Sacer". Para ello, se retomarán conceptos esenciales de su texto Homo Sacer, el poder soberano y la nuda vida. ${ }^{7}$ Allí, el autor italiano inicia su estudio distinguiendo dos conceptos que existían en la Grecia clásica para referirse a la "vida": el término Zoe, el cual expresaba el simple hecho de vivir, común a todos los seres vivos; y el término Bios, que nombraba la vida políticamente cualificada. Esta distinción limitaba la acción del poder político al campo comprendido por el Bios, mientras que excluía a la Zoe del espacio propio de la ciudad. De este modo, en la concepción política de la Grecia clásica - tal como aparece en Aristóteles- no todo lo viviente era objeto de la acción soberana, ya que hay unos límites claramente establecidos. En el desarrollo de la política occidental se asiste, como lo muestra la reflexión de Agamben, ${ }^{8}$ a una expansión de los límites del dominio soberano sobre la vida, es decir, a una difuminación de las fronteras que separaban la vida objeto del Derecho de aquella vida reservada a una existencia apolítica. Es así como el curso de la política en Occidente toma progresivamente la forma de una biopolítica, de una administración y un control totalizantes sobre la vida, que encuentra para Agamben su plena realización en el paradigma del campo de concentración.

Analizando los hechos ocurridos en el campo de Auschwitz, Agamben en su libro Homo Sacer III, ${ }^{9}$ desarrolla la sombría teoría que hace de la mayoría de los humanos ya no ciudadanos, sino meros objetos experimentales de la ciencia. En primer lugar, si hay un incremento del control político sobre las vidas, este control ya no se desarrolla a través de los aparatos tradicionales de control y sometimiento, sino a través de mecanismos que despojan de todo derecho o etiqueta jurídica. Por tal razón, la nutrición, los sistemas sanitarios, los hospitales, la eutanasia, el control de natalidad y hasta la misma definición de muerte

\footnotetext{
6. Id. Pág. 169.

7. Véase Giorgio Agamben. Lo Que Queda DE Auschwitz. El ARchivo y el testigo. Homo Sacer iII. Pre-textos. (2000).

8 Véase Giorgio Agamben, supra, nota 4.

9. Véase Giorgio Agamben, supra, nota 6.
} 
cerebral forman parte de un dispositivo que hace de los cuerpos meros bancos de órganos. En segundo lugar, existe una paradoja jurídica que puede dejar al sujeto dentro y fuera de la ley al mismo tiempo. Fuera de la ley, deja de ser un sujeto jurídico y se transforma en una mera existencia biológica, una "nuda vida". Con este concepto, Agamben se refiere a una zona de indistinción entre una vida protegida y reconocida por un orden jurídico y político dado, y la mera vida biológica, es decir, un "cuerpo biológico" en relación con el cual el reconocimiento y la protección jurídica quedan suspendidos. Desde que Agamben introdujo el concepto, con este se han intentado hacer inteligibles muchos de los fenómenos políticos de la época contemporánea. Así, con el concepto de biopolítica se ha posibilitado reordenar analíticamente fenómenos que provienen de distintos ámbitos y comprenderlos bajo un mismo suelo teórico y conceptual. Por ejemplo, los deportados en los campos nazis, la pobreza del denominado Tercer Mundo, la situación de los inmigrantes detenidos en aeropuertos internacionales, los detenidos en Guantánamo y los enfermos terminales en las salas de reanimación. Todos esos casos en los que en el ser humano se excluye a un sujeto de derechos y se configura como un "mero cuerpo" fuera del orden jurídico.

Para Agamben, ${ }^{10}$ el dispositivo que permite la emergencia de la nuda vida en el seno del espacio político es el estado de excepción, el cual transparenta de la manera más luminosa la esencia de la autoridad del Estado. Ahora bien, lo que sucede en el estado de excepción es que la vida no queda propiamente ni fuera ni dentro de la ley, sino que se relaciona con la ley a modo de una exclusión-inclusiva, ya que dicho estado de excepción se produce por la suspensión del Derecho, pero, al mismo tiempo, esa vida está fuera de la ley y a merced del poder soberano; en otros términos, en el estado de excepción la ley se aplica desaplicándose. En palabras del filósofo: "El Estado de excepción no es, pues, el caos que precede al orden sino la situación que resulta de la suspensión de éste. En este sentido la excepción es, verdaderamente, según su etimología sacada fuera (excapere)". ${ }^{11}$

Siguiendo la tesis de Agamben en la que ubica al campo de concentración como paradigma del espacio biopolítico, se avanza hacia el significado ético y político del exterminio. Por esta vía, Agamben plantea lo que él denomina "la aporía de Auschwitz", a saber, el problema que trae la no coincidencia entre

10. Véase Giorgio Agamben, supra, nota 4.

11. Véase Giorgio Agamben, supra, nota 6. Pág. 30 hechos y verdad, para finalmente arribar al lugar del testimonio.

\section{EL TESTIGO}

Primo Levi es un superviviente de los campos que se hace escritor con el único fin de testimoniar. Su interés se centra en la llamada "zona gris", en la cual las víctimas se convierten en verdugos y los verdugos en víctimas. En un campo, una de las razones que pueden impulsar a un deportado a sobrevivir es convertirse en un testigo. Justificar la propia supervivencia no es fácil y mucho menos en un campo. Por esto, el superviviente tiene la vocación de la memoria (siempre recuerda).

En muchos de los testimonios de los supervivientes se encuentran relatos acerca de la figura del musulmán, nombre con el cual se hacía referencia a aquel prisionero que había abandonado cualquier esperanza, no poseía estado de conocimiento y era abandonado por los compañeros; una suerte de cadáver ambulante. El musulmán de Auschwitz ha perdido cualquier forma de voluntad o de conciencia. El musulmán encarna el significado antropológico del poder absoluto de manera radical: al someter a las víctimas al hambre y la degradación, le permite establecer un tercer reino entre la vida y la muerte. Es el completo triunfo del biopoder sobre la humanidad. Aunque vivo, el musulmán es una figura sin nombre, y al imponer una condición así, el régimen encuentra su propio cumplimiento. Por eso su "tercer reino" es la cifra perfecta del campo, del no-lugar, y los campos no solo son de exterminio, sino un lugar de un experimento, más allá de la vida y la muerte, en donde el judío se transforma en musulmán y el hombre en el no-hombre. Que siga habiendo vida en la degradación más extrema es el mensaje atroz que los supervivientes llevan del campo. El musulmán es el guardián del umbral de una ética y de una forma de vida que empieza donde la dignidad se acaba. En este sentido, el musulmán es el nombre de lo intestimoniable.

¿Cómo es posible entonces dar testimonio de lo intestimoniable? Esta es la paradoja que constituye el núcleo del testimonio, tal como aparece en los relatos de Levi. La posibilidad del testimonio toma cuerpo en la posibilidad de acceder a la palabra y de tener algo que decir. Sin embargo, el único testigo integral del campo, a saber, el musulmán, es alguien que ha sido arrancado del circuito de la palabra, y quien teniendo todo para decir no puede hablar. En el otro polo del testimonio encontramos al superviviente 
como aquel que teniendo la posibilidad de hablar, no tiene realmente nada que decir. Es posible entender lo anterior afirmando que el testimonio se sostiene entre un polo de subjetivación y un polo de desubjetivación: el testigo integral del campo es el resultado de una desubjetivación radical que lo priva de toda posibilidad de dar testimonio, mientras que aquel que aún puede mantener una posición subjetiva no puede hablar más que haciendo suya, de alguna manera, la experiencia innombrable del musulmán. De lo anterior resulta que el fundamento de la subjetividad está en el ejercicio de la lengua y lo que llamamos conciencia es el aflorar de una propiedad lingüística. La subjetividad se articula con la desubjetividad, así como el superviviente se articula con el musulmán, el hombre (superviviente) se articula con el no-hombre, y entonces la subjetividad de la conciencia de la palabra se articula con la desubjetividad del que no habla. El testimonio es así inherente a la lengua y atestigua su autoridad en relación con que el testigo puede hablar únicamente en nombre de un no-poder decir, o sea, de un ser sujeto, y esta es la única apuesta ética después de Auschwitz.

\section{LO FEMENINO COMO RESPUESTA}

\section{AL DISCURSO SOCIOPOLÍTICO MODERNO}

Ahora bien, en el marco de este panorama, el psicoanálisis ofrece herramientas conceptuales y teóricas que permiten abordar también la cuestión de la biopolítica y sus consecuencias en la configuración subjetiva, pero a su vez, provee una vía alterna a este "tercer reino" que ha impuesto el discurso político moderno. Se hace referencia a la contraposición que desarrolla Lacan en sus fórmulas de la sexuación, entre lógica masculina y lógica femenina. Dos modos que hacen referencia a dos maneras distintas de habitar el lenguaje.

La lógica masculina opera, en su estructura, de la misma forma que el estado de excepción, por cuanto en ambos el padre está en la misma posición de excepcionalidad que el soberano: existe un $\mathrm{x}$ (el padre) que no está inscrito en la función fálica y que no está sometido a la castración. Sin embargo, paradójicamente, al exceptuarse de la ley, él mismo se incluye porque la instaura. Esta es la manera de operar de la función fálica: cuando al menos uno queda excluido de ella, permite que todos los otros asistan a ella.
Entonces, desde el psicoanálisis, la biopolítica opera en razón a la necesidad subjetiva del discurso del padre, todo esto provisto de la idealización del objeto que se pretende alcanzar mientras el sujeto se encuentra en el limitado campo de la normatividad que está incluido en la concepción actual de Estado, pretendiendo que este sea el único mecanismo de cohesión entre los individuos que están dentro, y teniendo como resultado la proyección en la que el Derecho y el soberano están en todo aspecto de la vida; ese el único discurso conocido y el único discurso que el individuo está dispuesto a mantener.

Ahora, como tema trascendental y segundo punto, se da paso a una serie de incógnitas que permitirán vislumbrar la inconsistencia de la estructura social y lo innovador que representaría poder pensar y actuar diferente. Por tal razón, es determinante en la búsqueda de las posibilidades que permitan descubrir un discurso distinto al masculino predominante en la sociedad, para lo cual vale la pena plantear una serie de interrogantes que ayudarán a bordear esta cuestión: ¿será que hay algo más allá del padre y su discurso que determina todo lo que conocemos?, y, si el lenguaje es fálico, ¿cómo se nombra lo femenino? ¿Cuál es la definición de lo femenino y puede este concepto contraponerse al discurso actual?

En este sentido, se puede afirmar que en la lógica femenina no opera la excepción; nada hace la excepción en la función fálica, por lo que la función fálica es no-toda. Por esto Lacan explica el lado femenino a partir de la lógica de la inconsistencia - una lógica diferente-, en la que el conjunto siempre permanece abierto y los sujetos pueden hacer lazo a partir de su singularidad. De ahí que Lacan afirme que "el sujeto, la mitad en la que se determina de los cuantificadores negados, es porque nada existente haga límite de la función y por eso no podría asegurarse en nada que tuviera que ver con un universo. Así, fundándose por esa mitad, ellas son no-todas". ${ }^{12}$ Esta forma de habitar no-todo el lenguaje se puede relacionar con lo desarrollado por Agamben en relación con el testimonio, dado que solo se da en la posibilidad de la no-palabra.

Esta manera de subjetivarse en una desubjetivación se puede observar también en la operación artística, campo al que también apela Agamben en su reflexión cuando se refiere a la función del poeta, al indicar que el poeta siempre es otro personaje en cuya alma vive. A esta cuestión también se refiere Freud

12. Véase Carmen Gallano. La alteridad femenina. Asociación de Foro del Campo Lacaniano de Medellín. (2000). 
en una carta que le dirige a Albert Einstein sobre la cuestión de la guerra, en la que afirma: "Entretanto tenemos derecho a decirnos: todo lo que promueva el desarrollo de la cultura trabaja también contra la guerra". ${ }^{13}$ Cabe anotar que cuando Freud se refiere al desarrollo de la cultura, está haciendo alusión al lugar que tiene fundamentalmente el arte como la más elevada expresión de las producciones culturales.

\section{Arte y POlítica: Algunos ELEMENTOS PARA LA DISCUSIÓN}

Una escena escalofriante se erige como el recuerdo constante de muchos de los habitantes de este país, cuya estructura puede expresarse así: una tarde de mi remota niñez, andaba con mi madre en las orillas del río Magdalena cuando por sus aguas bajaba un torso, solo, sin brazos, sin piernas, sin cabeza.

Dicha imagen da cuenta de uno de los elementos sobre los que vuelven las expresiones artísticas que se han construido en torno a la guerra en Colombia, a saber: el asunto de los duelos irresueltos, de los cadáveres insepultos que atraviesan de cabo a rabo este país. Se trata de un cadáver más de los cientos de miles que hay acá en Colombia y de los que hubo en América Latina, producto de las alianzas criminales del Estado con los asesinos a sueldo que, sin ley ni dios, descuartizaban con motosierras a sus ciudadanos. Sobre esto, tal vez resulte pertinente retomar aquellas líneas prometeicas de García Márquez al aceptar el Nobel: "hemos de pedirle muy poco a la imaginación, porque el desafío mayor para nosotros ha sido la insuficiencia de los recursos convencionales para hacer creíble nuestra vida". ${ }^{14}$ Ese es el costo de una violencia, de un conflicto interno existente y que a diario solo produce barbarie, víctimas, despojos y miseria, cadáveres picados y acribillados, cadáveres entregados a los caudales de los ríos, insepultos; esto solo es el lazo social roto. Pero estos acontecimientos son inocuos en su prístina estructura social porque solamente son vistos desde un entorno de leyes como homicidios, desapariciones forzadas, torturas... un mar de artículos jurídicos desconectados con el lazo social que solo sirven para las

13. Véase Sigmund Freud. ¿Por qué la guerra? (Einstein y Freud) Obras Completas: Sigmund Freud (Vol. 22). Amorrortu (2006). Pág. 198.

14. Véase Gabriel García Márquez. Discurso de ACEPtación del Premio Nobel: La soledad de América latina. (1982). Disponible en http://www.nobelprize.org/nobel_prizes/literature/ laureates/1982/marquez-lecture-sp.html estadísticas y la publicidad. ¿Es Colombia consciente como sociedad de toda esta barbarie y podrá reivindicar el tejido social de manera efectiva? ¿Cuáles son los caminos que se deben recorrer para cerrar esas cicatrices dolorosas de la guerra? ¿América Latina ha superado de manera efectiva esa época de horror y demencia? Baste retomar de nuevo a Gabriel García Márquez:

El general Antonio López de Santana, que fue tres veces dictador de México, hizo enterrar con funerales magníficos la pierna derecha que había perdido en la llamada Guerra de los Pasteles. El general García Moreno gobernó al Ecuador durante 16 años como un monarca absoluto, y su cadáver fue velado con su uniforme de gala y su coraza de condecoraciones sentado en la silla presidencial. El general Maximiliano Hernández Martínez, el déspota teósofo de El Salvador que hizo exterminar en una matanza bárbara a 30 mil campesinos, había inventado un péndulo para averiguar si los alimentos estaban envenenados, e hizo cubrir con papel rojo el alumbrado público para combatir una epidemia de escarlatina (...) No hemos tenido un instante de sosiego. Un presidente prometeico atrincherado en su palacio en llamas murió peleando solo contra todo un ejército, y dos desastres aéreos sospechosos y nunca esclarecidos segaron la vida de otro de corazón generoso, y la de un militar demócrata que había restaurado la dignidad de su pueblo. En este lapso ha habido 5 guerras y 17 golpes de Estado, y surgió un dictador luciferino que en el nombre de Dios lleva a cabo el primer etnocidio de América Latina en nuestro tiempo. Mientras tanto 20 millones de niños latinoamericanos morían antes de cumplir dos años, que son más de cuantos han nacido en Europa occidental desde 1970.

Esta es una denuncia efectuada en 1982 y está aún vigente.

Ante la interrogación por el lugar del artista en lo social, se debe afirmar que el escritor es un revolucionario, el pintor es un revolucionario, el músico es un revolucionario, el arte es revolución. Lo anterior explica que sean los artistas los primeros en ser desterrados o acallados por los gobiernos, como le ocurre al escritor turco Orhan Pamuk en la actualidad, u otrora a los artistas argentinos desterrados por la dictadura militar, o con el asesinato del abogado y humorista político Jaime Garzón en Colombia. Estos sucesos no son de balde, son producto de la denuncia, de la grieta que los artistas hacen visible y devela el rostro de quien ostenta el poder. Es la muestra fehaciente de la denuncia que muestra la falta y, de manera particular 
y fulminante, logra evidenciar ante el lazo social los hechos del amo, en términos del psicoanálisis. Es por ello que las caricaturas, la música protesta, los poemas sociales y la literatura se convierten en los principales opositores de quien ostenta el poder, dada su fuerza arrolladora de denuncia. Ahora bien, esta loable actividad se configura con ese "bordear el vacío", con sublimar el dolor, la desaparición, la falta, intentando subsanar las heridas y logrando así reconstruir el tejido social destruido por el discurso masculino, es decir, el discurso del amo, y es esta denuncia una vía alterna que no opera bajo las coordenadas del discurso del gobernante, sino de lo trascendente, de lo artístico, denominándose "el discurso femenino". No obstante, este discurso femenino no se debe interpretar con la feminidad, sino con el rol artístico de la sociedad como vía alterna de respuesta al discurso del poder que no está dentro de su ámbito, por ello no le es aprehensible. Es así que un artista no se venga a muerte, sino que denuncia con su obra. Es así como se pueden encontrar miles de páginas de letras felices que señalan las atrocidades de los gobiernos, no disparan armas, ni tienen presos políticos, ni legislan para acrecentar sus cuentas bancarias, ni callan ante el otro; solo denuncian y hacen visibles las atrocidades. Como ejemplo se puede retomar la valentía de las madres de Soacha, quienes denuncian los atroces actos reseñados por la prensa internacional bajo el titular "Así se fabrican guerrilleros muertos":

Miembros del Ejército colombiano secuestraban a jóvenes de barriadas marginales, los trasladaban a cientos de kilómetros de sus casas, allí los asesinaban y los hacían pasar por guerrilleros muertos en combate, para cobrar así las recompensas establecidas en secreto por el Gobierno de Álvaro Uribe. De ahí el término "falsos positivos", en referencia a la fabricación de las pruebas. Diecinueve mujeres, cuyos hijos fueron secuestrados y asesinados por el Ejército a principios de 2008, fundaron el grupo de las Madres de Soacha para exigir justicia. A mediados de 2013, la Fiscalía General contaba 4.716 denuncias por homicidios presuntamente cometidos por agentes públicos (entre ellos, 3.925 correspondían a falsos positivos). Navanethem Pillay, alta comisionada de las Naciones Unidas para los derechos humanos, denuncia que las investigaciones son muy escasas y muy lentas, que los militares vinculados a los crímenes continúan en activo, que incluso reciben ascensos, y que sus delitos gozan de una impunidad sistémica. ${ }^{15}$

15. Ander Izagirre. Asíse fabrican guerrilleros muertos. El PAís. Marzo 26 de 2014. Disponible en http://elpais.com/elpais/2014/03/06/planeta futuro/1394130939_118854.html
Estas valientes mujeres hacen su denuncia por medio del dispositivo artístico, haciendo propia la tragedia de Sófocles al titular su apuesta en escena: Antígonas-Tribunal de Mujeres. Resuenan en la propuesta que realizan acompañadas por la Corporación Colombiana de Teatro las voces de sus hijos desaparecidos, así como las de tantos otros afectados por la violencia política del país, posibilitando procesos de duelo que son a la vez subjetivos y políticos. Por esta vía resurge la etimología de la palabra "arte", la cual tiene su raíz en el latín arts, artis, y el Diccionario de la Real Academia Española la define como: "Virtud, disposición y habilidad para hacer algo. Manifestación de la actividad humana mediante la cual se expresa una visión personal y desinteresada que interpreta lo real o imaginado con recursos plásticos, lingüísticos o sonoros." Es por ello que la artista colombiana Doris Salcedo, consciente de su papel de artista en la sociedad, el 9 de octubre de 2007 en el museo Tate Modern de Londres:

[...] causó un impacto profundo: en vez de poner una escultura en el espacio, Salcedo lograba desconcertar al mundo del arte al abrir una grieta profunda en el piso del hall, que lo atravesaba de principio a fin. La obra era un vacío. Una intrusión brutal en el espacio, una herida insolente, y lograba reproducir metafóricamente para el espectador el eco de un dolor sordo, un extraño tajo de silencio y horror. ${ }^{16}$

Es en virtud de su comprometido trabajo como artista que denuncia. Dice Salcedo: "Creo que el arte es capaz de señalarle a la sociedad caminos hacia dónde mirar, no imponerlos sino mostrar opciones (...) El arte le hace contrapeso a la barbarie y a una realidad muy compleja". ${ }^{17}$

\section{REFERENCIAS}

Ander Izagirre. Así se fabrican guerrilleros muertos. El PAís. Marzo 26 de 2014. Disponible en http://elpais.com/ elpais/2014/03/06/planeta_futuro/1394130939_118854.html

16 Arcadia. La grieta. Revista Arcadia. Enero 22 de 2013 Disponible en http://www.revistaarcadia.com/opinion/editorial/ articulo/la-grieta/30934

17. Nelson Fredy Padilla. El arte es el contrapeso de la barbarie. El Espectador. Mayo 8 de 2010. Disponible en http://www. elespectador.com/impreso/cultura/articuloimpreso-202179-el-arte -el-contrapeso-de-barbarie 
Arcadia. La grieta. Revista Arcadia. Enero 22 de 2013. Disponible en http://www.revistaarcadia.com/opinion/ editorial/articulo/la-grieta/30934

Carmen Gallano. La alteridad femenina. Asociación de Foro del Campo Lacaniano de Medellín. (2000).

Giorgio Agamben. Homo SACER. El Poder Soberano y LA NUDA VIDA. Pre-textos. (1998).

Giorgio Agamben. Lo QUe QuedA DE Auschwitz. El ARChivo y el testigo. Homo Sacer iII. Pre-textos. (2000).

Gabriel García Márquez. Discurso de ACEPTACión DEL Premio Nobel: La soledad de América Latina. (1982). Disponible en http://www.nobelprize.org/ nobel_prizes/literature/laureates/1982/marquez-lecture-sp.html

Nelson Fredy Padilla. El arte es el contrapeso de la barbarie. El Espectador. Mayo 8 de 2010. Disponible en http:// www.elespectador.com/impreso/cultura/articuloimpreso-202179-el-arte-el-contrapeso-de-barbarie

Néstor Braunstein. Los dos campos de la subjetividad: Derecho y Psicoanálisis. Gerez Ambertín, Ed. CulPA, RESPONSABILIDAD Y CASTIGO EN EL DISCURSO JURÍDICO Y PSICOANALÍTICo VoL. 1. Letra Viva. (2006). Págs. 11-24.

Mauricio García Villegas. Un país de estados de excepción. Elespectador.com. Octubre 11 de 2008. Disponible en http://www.elespectador.com/impreso/politica/articuloimpreso43317-un-pais-de-estados-de-excepcion

Michel Foucault. Historia DE LA SEXUALIDAd i. LA VOLUNTAD DE SABER. Fondo de Cultura Económica. (2007).

Pierre Bruno. ¿Qué Es UNA LEY? Escuela de Estudios en Psicoanálisis y Cultura, Universidad Nacional de Colombia [inédito].

Sigmund Freud. ¿Por qué la guerra? (Einstein y Freud). Obras Completas: Sigmund Freud (Vol. 22). Amorrortu. (2006). 